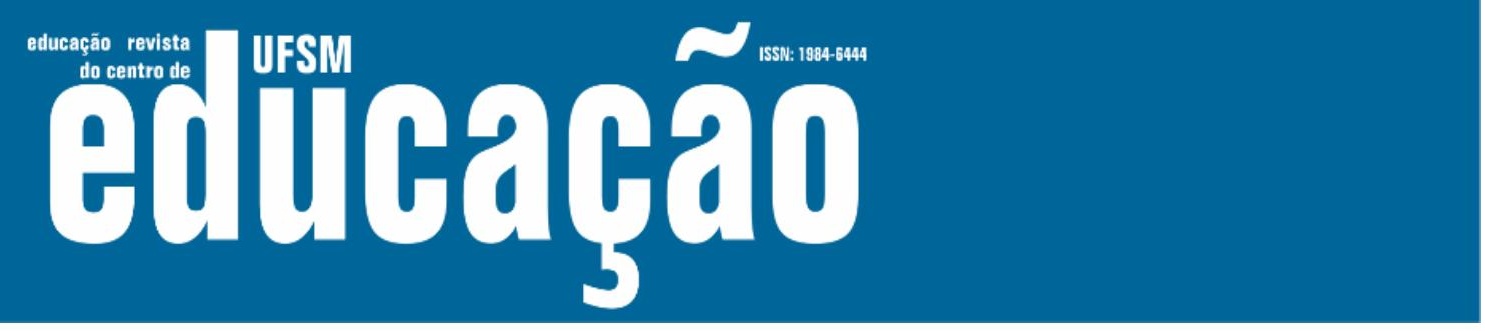

ISSN: 1984-6444 | http://dx.doi.org/10.5902/1984644463197

\title{
Percepções sobre extensão por parte dos docentes e discentes de graduação
}

\author{
Perceptions about the extension by teachers and graduates
}

\begin{abstract}
Leopoldina Francimar Amorim Coelho Diniz
Mestra egressa da Universidade Federal do Vale do São Francisco. Petrolina, Pernambuco, Brasil. leopoldina.amorim@ifsertao-pe.edu.br - https://orcid.org/0000-0001-6337-5414
\end{abstract}

Geida Maria Cavalcanti de Sousa

Professora doutora na Universidade Federal do Vale do São Francisco. Petrolina, Pernambuco, Brasil. geida.cavalcanti@gmail.com - https://orcid.org/0000-0001-9466-7559

Dennis Marinho Oliveira Ramalho de Souza

Professor doutor na Universidade Federal do Vale do São Francisco. Petrolina, Pernambuco, Brasil. dennismarinho@gmail.com - https://orcid.org/0000-0001-6692-2647

Recebido em 23 de novembro de 2020

Aprovado em 25 de outubro de 2021

Publicado em 24 de fevereiro de 2022

\section{RESUMO}

Diante da importância da temática extensão universitária no Brasil, desde o final do séc. XIX, sendo incluída como a terceira missão da universidade, juntamente ao ensino e a pesquisa, buscou-se adentrar neste contexto, acompanhando essa conquista que, aos poucos, vem adquirindo mais espaço e sendo passível à distorções. Constam, nesse relatório, os resultados da pesquisa realizada no Instituto Federal do Sertão Pernambucano, especificamente no campus Petrolina, cujo objetivo foi analisar a percepção dos discentes e docentes dos cursos superiores com relação à extensão frente as suas políticas, ações e diretrizes. Numa abordagem quantitativa, foi aplicado questionário online, tipo escala Likert, com os docentes ativos nos cursos superiores e discentes matriculados em cursos superiores de Licenciaturas em Música, Computação, Química, Física e no curso de Tecnologia de Alimentos do segundo semestre de 2019. O contato com os participantes foi por e-mail, via WhatsApp e com visitas in loco. Os resultados apontam que o campus Petrolina está politicamente ativo e engajado em desenvolver ações de extensão, sendo perceptível pela maioria dos pesquisados, mesmo identificando-se algumas lacunas na comunicação, nas possibilidades de atuação e aprofundamento nas diretrizes extensionistas. Conclui-se que a extensão está sendo praticada pelos interlocutores, necessitando, ainda, aprofundar os conhecimentos com relação ao conceito, diretrizes e possibilidades extensionistas.

Palavras-chave: Extensão, Percepção da Extensão, Extensão Universitária, Extensão Tecnológica, Práticas de Extensão. 


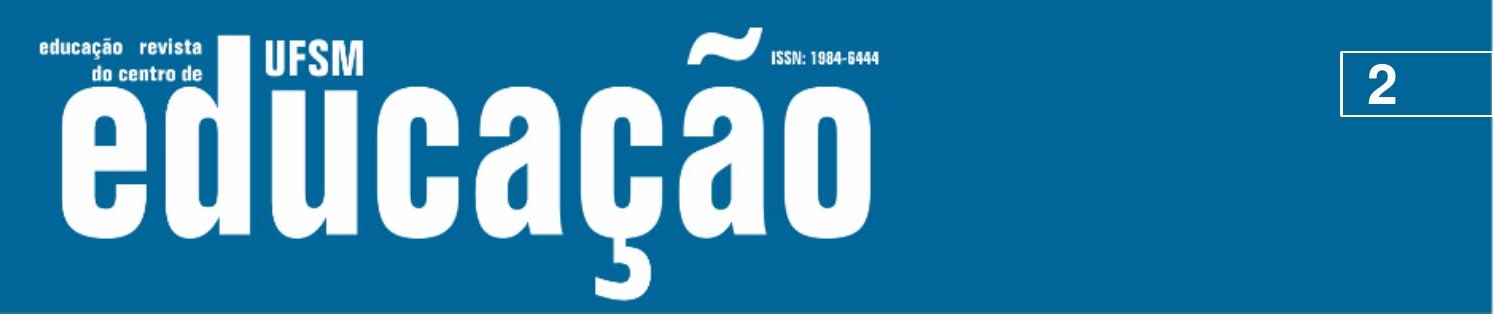

ISSN: 1984-6444 | http://dx.doi.org/10.5902/1984644463197

\section{ABSTRACT}

Given the thematics' importance of the university extension in Brazil, since the end of the century. XIX, being included as the third mission of the university, along with teaching and research, we sought to enter this context, following this achievement that is gradually acquiring more space and becoming more susceptible to distortions. This report contains the results of the research thats was carried it out at the Federal Institute of Sertão Pernambucano, specifically on Petrolina campus, whose objective was to analyze the perception of students and professors of higher education courses regarding extension in relation to their policies, actions and guidelines. In a quantitative approach, an online questionnaire, a Likert scale type, was applied, with active teachers in higher education courses and students enrolled in higher education courses in Music, Computing, Chemistry, Physics and Food Technology course in the second semester of 2019. Contact with participants was by e-mail, via Whats-App and with on-site visits. The results show that the Petrolina campus is politically active and engaged in developing extension actions, being noticeable by the majority of those surveyed, even though some gaps were identified in the communication, the possibilities of action and deepening the extension guidelines. It is concluded that the extension is being practiced by the interlocutors, still needing to deepen the knowledge in relation to the concept, guidelines and extension possibilities.

Keywords: Extension, Perception of Extension, University Extension, Technological Extension, Extension Practices.

\section{Introdução}

O sistema Educacional de cursos profissionais e tecnológicos passou por várias mudanças ao longo de sua trajetória no Brasil, que ocorreram na atual conjuntura política brasileira, tanto na sua aplicação quanto na sua estrutural legal. Registros bibliográficos reportam que, desde a época do Brasil Império, sendo destaque o chamado período do ouro, já se falava no desenvolvimento de aprendizagens laborais. (BRASIL, 2018)

Ao longo dos anos, de acordo com as condições econômicas do país, o ensino profissionalizante se adequou para atender as diversidades da economia brasileira. $\mathrm{Na}$ efetivação da Lei de Diretrizes e Bases da Educação Nacional, em 1961, ํㅜำ 4.024/61 (LDB), primeira Lei aplicada à espécie, ficou assegurado, aos discentes concluintes dos cursos de educação profissional, a sua continuidade nos estudos e seu ingresso no ensino superior. 


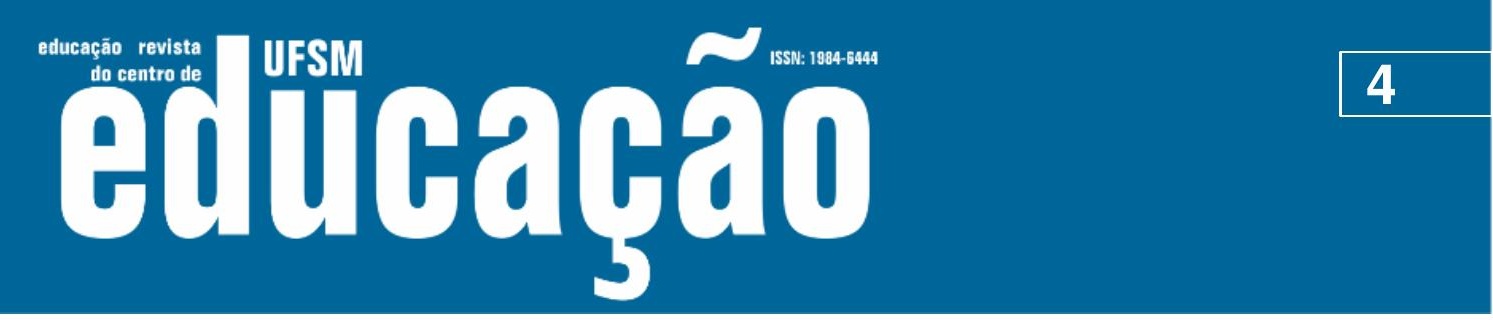

ISSN: 1984-6444 | http://dx.doi.org/10.5902/1984644463197

percepção dos discentes e docentes com relação à extensão, por meio da aplicação de questionário desenvolvido por Barbosa (2012).

Para Barbosa (2012), quando desenvolveu sua pesquisa sobre a percepção dos discentes, na Universidade Federal de Minas Gerais (UFMG), já observava a necessidade de que fossem implantados instrumentos avaliativos adequados à realidade de cada instituição.

Santos, Rocha e Passaglio (2016) expõem a significativa relação entre a extensão e a formação profissional e por isso buscaram compreender as concepções dos discentes sobre o processo extensionista. Ferreira Júnior (2018), entre as conclusões da sua pesquisa, salienta a necessidade de implementar ações rotineiras, tanto para avaliação como para acompanhamento no desenvolver destas ações extensionistas, posição defendida por Barbosa (2012), ao afirmar a existência de lacunas que merecem ser observadas no que diz respeito à divulgação eficiente da extensão em todas as suas esferas.

Paulo Freire (1968), destacado historiador e filósofo que estudou a extensão rural e a educação popular, traz a necessidade de que a extensão seja uma ação dupla na troca de conhecimento, entre o saber científico/universitário e o saber prático advindo das comunidades.

A extensão no Brasil surgiu da influência dos movimentos populares na Europa, pelos modelos norte americano de educação, e pelo manifesto de Córdoba que contou com a participação marcante dos discentes, reivindicando a abertura da universidade com ações junto à comunidade. No final dos anos 1800, a extensão, passo a passo, ganhou importância no seio universitário e se tornou o terceiro pilar que sustenta o fazer da universidade. (SANTOS, 2016)

Com a Constituição Brasileira de 1988, a extensão alcançou nova dimensão, quando a Lei determinou a indissocialização entre as três esferas da educação, o ensino, a pesquisa e a extensão. Tal pensamento foi ratificado pela Lei de Diretrizes e Bases (LDB/1996) que regulamenta a educação brasileira, e pelo dinamismo dos Fóruns de Extensão, o Forproex - O Fórum de Pró-Reitores de Extensão das Instituições Públicas de Educação Superior Brasileiras e Forproext - Fórum de PróReitores de Extensão da Rede Federal e Tecnológica. 


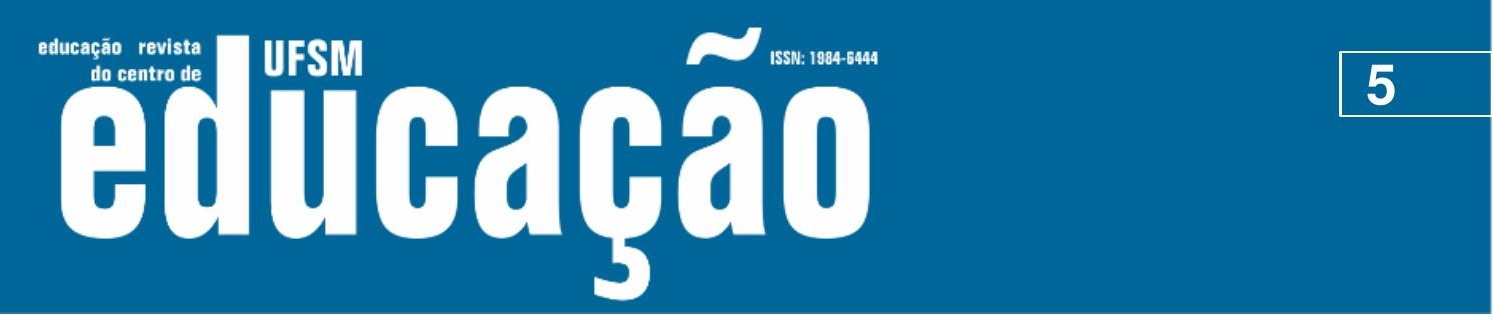

ISSN: 1984-6444 | http://dx.doi.org/10.5902/1984644463197

O IF Sertão-PE faz parte da Rede Federal de Educação Profissional e Tecnológica, tendo, em 2019, sua composição por 661 unidades, distribuídos em 644 campi nos estados brasileiros, além desses, há os que não migraram para Institutos Federais, que são 22 escolas com vínculo à Universidade, o Colégio Pedro II, os CEFETs de MG e RJ e uma Universidade Tecnológica no estado do Paraná. (BRASIL, 2018)

O crescimento do ensino de aspecto profissionalizante abriu espaço para que se pudesse ofertar, à sociedade, uma educação, além de habilitada com profissionais aptos ao exercício profissional eficiente, mas também pessoas que reconheçam o contexto social no qual estão inseridos, oportunizados pelas práticas extensionistas propostas pelas instituições de ensino.

O interesse pela pesquisa veio da participação desta pesquisadora em eventos de extensão em 2014, tendo contato com as atividades extensionistas desenvolvidas pelos discentes da instituição. Tais práticas foram despertando a curiosidade em descobrir como os interlocutores entendiam a extensão. Assim, essa pesquisa analisou a percepção dos discentes e docentes dos cursos superiores com relação à extensão frente às suas políticas, ações e diretrizes.

A região do Vale do São Francisco, sede da pesquisa, destaca-se por ser um dos maiores pomares de fruticultura irrigada do nosso País. O IF Sertão-PE, com seus campi distribuídos no sertão nordestino, oferta cursos voltados aos arranjos produtivos locais, almejando o desenvolvimento na perspectiva da sustentabilidade, atendendo inclusive com capacitações voltadas ao aproveitamento das frutas, às novas tecnologias e a formação docente, buscando formar profissionais emancipados para atuarem em diversos segmentos.

\section{Metodologia da Pesquisa}

A presente pesquisa de campo, com abordagem quantitativa, ocorreu no campus Petrolina do IF Sertão-PE. Foram incluídos os discentes e docentes dos cinco cursos superiores do campus referente ao segundo semestre do ano de 2019, excluindo todos os demais discentes e docentes dos cursos médio integrado, médio 


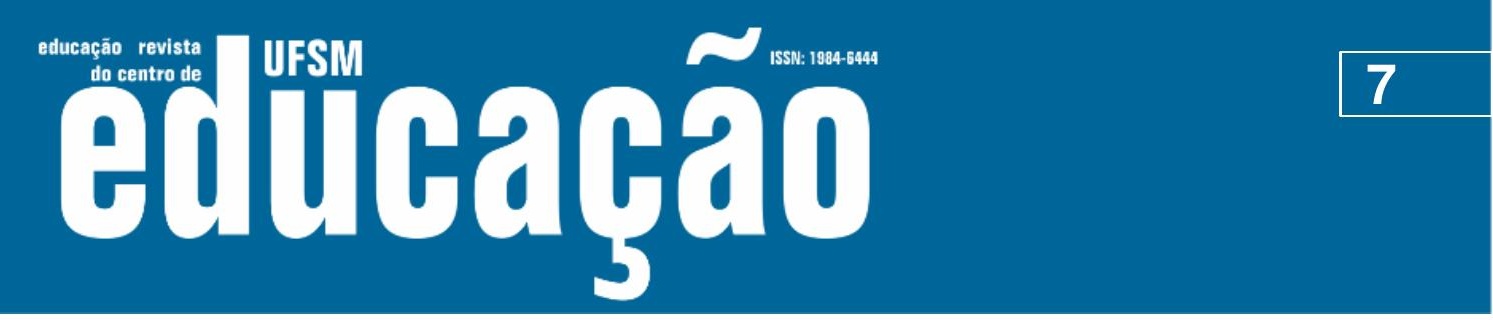

ISSN: 1984-6444 | http://dx.doi.org/10.5902/1984644463197

sendo testada a amostragem mínima exigida para cada cenário, tendo para Acesso e Participação 88 a 89 participantes, para Diretrizes 20, e para Impacto 24 a 25 participantes. No questionário docente, foram testados dois cenários: Acesso e Participação com a amostragem mínima exigida de 29 a 30 participantes e, para Diretrizes, 1 a 13 participantes (VIEIRA, 2015).

Com a suspensão das atividades acadêmicas, por causa da pandemia do novo Coronavírus (COVID-19) no mês de março, impossibilitando a aplicação presencial dos questionários impressos, optou-se pelo encerramento da pesquisa no mês de abril de 2020, concluindo o recebimento online com 225 respostas discentes e 36 docentes, atingindo o nível de confiabilidade.

Para a análise da qualidade dos questionários, utilizou-se Alpha de Cronbach, tendo obtido, no questionário discente para Acesso e Participação em 0.87 , quanto às Diretrizes 0,75 e quanto ao Impacto, 0,84. Para o questionário docente, obteve-se para Acesso e Participação 0,78 e Diretrizes 0,82, ou seja, os questionários estão bem avaliados e dimensionados (VIEIRA, 2015).

Com relação aos questionários, a escala Likert foi adotada para realizar a conversão dos dados Ordinais em dados Discretos, escalonando as atitudes quando o respondente indica seu grau de opinião com relação à determinada pergunta, tornando as respostas objetivas, direta e de múltipla escolha. A média ponderada pode variar de 0 a 10, considerando o cálculo de transformação dos dados tabelas entre: Nunca (0), Raramente (2,5), Não Sabe (5), Frequentemente $(7,5)$ e Sempre (10). Na etapa de interpretação dos resultados adquiridos com os participantes, utilizou-se o programa $R$-Statistics, para cada pergunta aplicada aos discentes e aos docentes, nos cenários divididos estatisticamente.

\section{Resultados e Discussões}

Os resultados e discussões serão apresentados em dois tópicos: o primeiro, referente à percepção dos discentes e o segundo, à percepção dos docentes. 


\section{T- ussm,

ISSN: 1984-6444 | http://dx.doi.org/10.5902/1984644463197

Figura 1 - Conhecimento da extensão

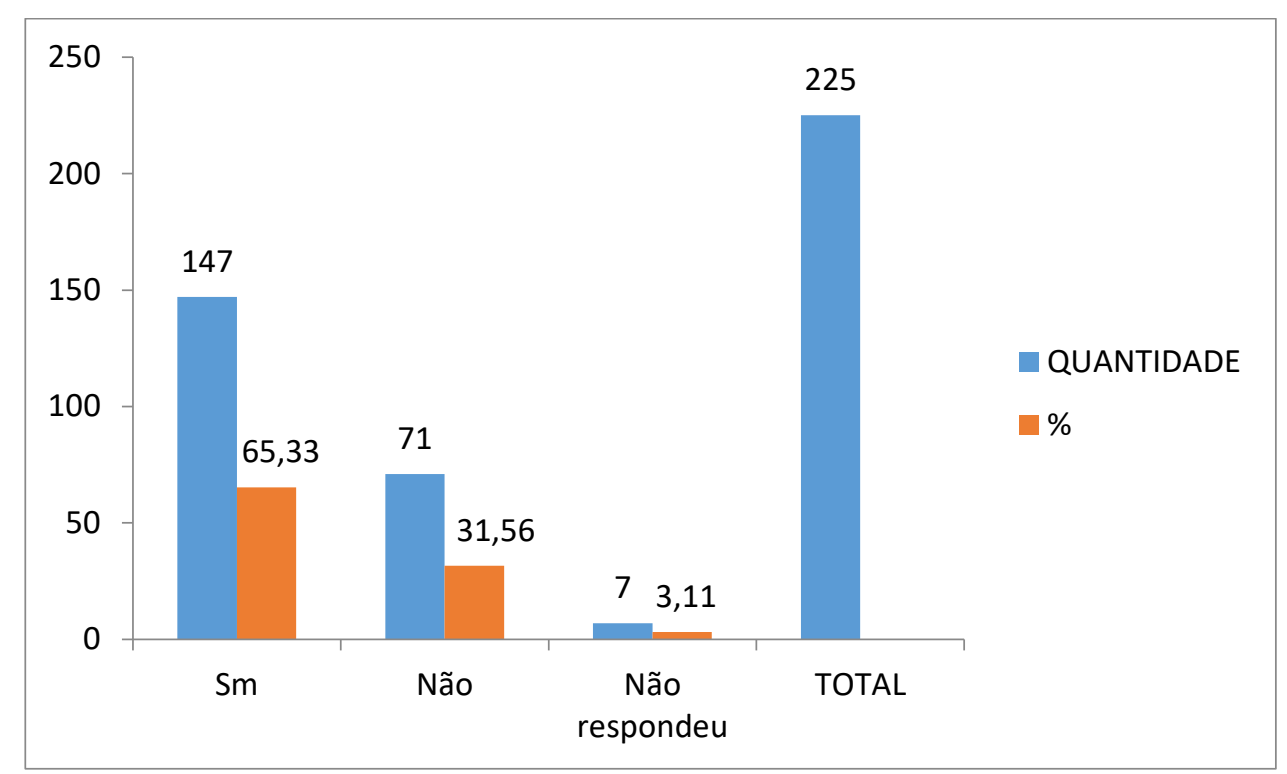

Fonte: Elaborado a partir do questionário aplicado durante a pesquisa de novembro 2019 a abril 2020.

Tal resultado percentual não prejudicou as análises, porque quem afirmou não conhecer, foi encaminhado para a pergunta número 42, identificando o principal motivo que dificulta a não participação das atividades de extensão, sendo que mais da metade dos pesquisados tem conhecimento da extensão executada pelo campus.

O conhecimento possibilita a tomada de decisões e escolhas, ampliando a consciência humana. Quando se conhece a extensão, tem-se a possibilidade de escolher entre praticá-la e desenvolver a percepção de quais transformações são proporcionadas pelas ações executadas, tanto para a comunidade, quanto na formação pessoal e acadêmica. Aggio (2016) expõe que, para Aristóteles, conhecer é de certa maneira perceber, e do ponto de vista Platônico, quem conhece previamente, tem mais condições de escolhas.

Serão apresentadas as análises com relação aos cenários que foram divididos nas perguntas do questionário quanto ao Acesso/Participação, às Diretrizes e ao Impacto para os discentes que participam das atividades extensionistas. 


\section{Aillbapẫ \\ 3}

ISSN: 1984-6444 | http://dx.doi.org/10.5902/1984644463197

indígena. Nas análises, os discentes declarados de etnia branca e parda estão com percepção quanto ao acesso/participação, ficando no nível de "raramente". Já os de etnia preta e amarela estão com nível de percepção "não sabe". Esses dados, comparados ao número de matriculados, mostram que existem mais discentes de cor branca e parda, em relação às outras etnias.

A Figura 2 mostra as perguntas de 10 a 19, que foram direcionadas a todos os participantes da pesquisa, objetivando identificar a percepção dos discentes com relação ao acesso/participação nas ações de extensão executadas pelo campus:

Figura 2 - Acesso/Participação Discente

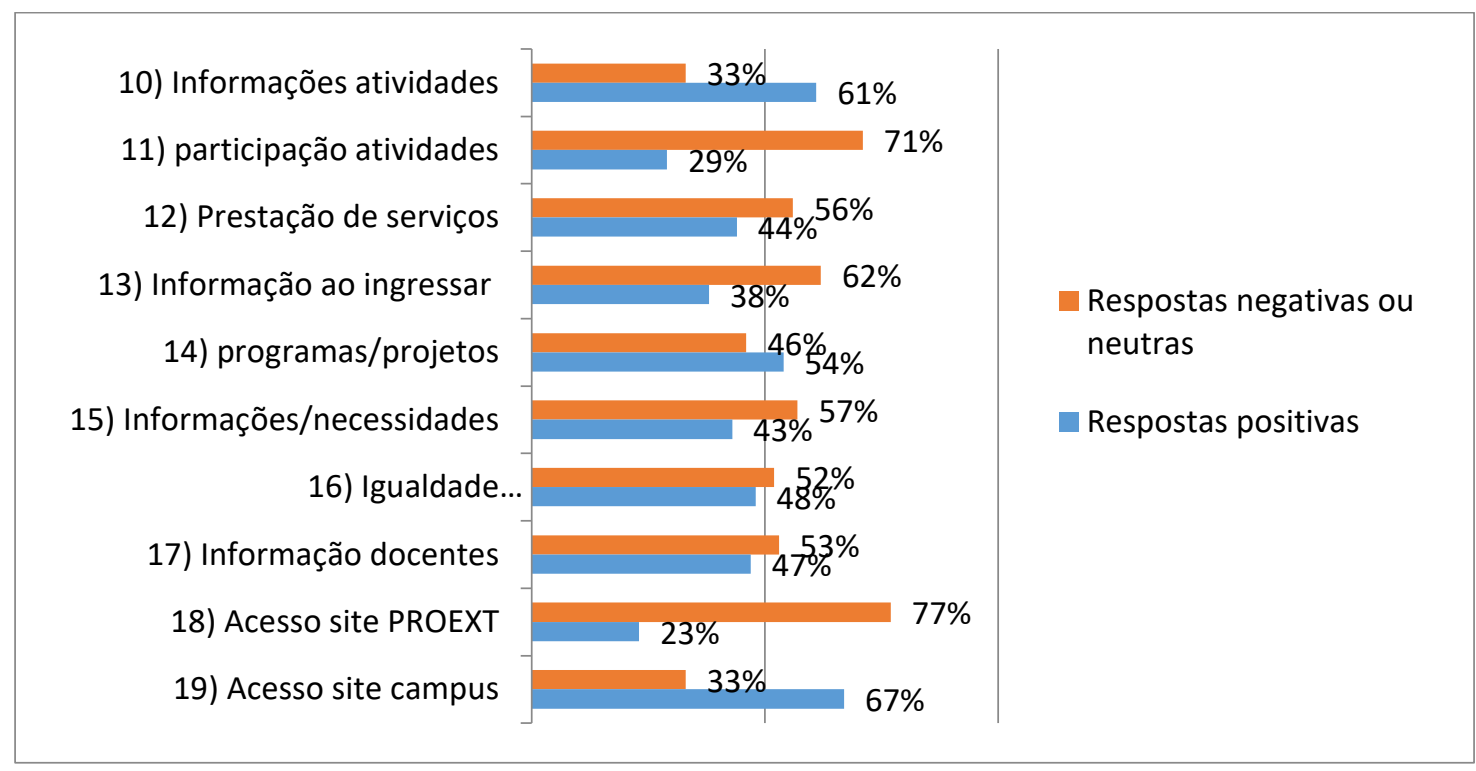

Fonte: Elaborado a partir do questionário aplicado durante a pesquisa de novembro 2019 a abril 2020.

Nesse aspecto, as médias estão variando entre 3,18 a 6,47 na escala Likert, ficando entre "raramente", "não sabe" e "frequentemente". Quando questionados se receberam informações ou se ficaram sabendo das atividades de extensão, conforme figura 3, os dados mostraram que mais da metade ficaram sabendo das atividades extensionistas que aconteceram, entretanto, $71 \%$ desses não estão participando dessas atividades, ou não estão identificando todas as possibilidades de extensão que são disponibilizadas. 


\section{Aillbapẫ \\ 3}

ISSN: 1984-6444 | http://dx.doi.org/10.5902/1984644463197

Observa-se nas perguntas 12, 13 e 14, que as médias estão bem próximas do nível de percepção de "não sabe". Identificou-se, nessas médias, que os discentes não conheciam o que se caracteriza como extensão, merecendo mais aprofundamento em conhecer seu conceito e suas possibilidades de atuação. Isso ficou mais perceptível, quando questionados sobre as divulgações das ações de extensão, os discentes identificaram como "não sabe" na pergunta 15, estando bem próximo quanto às informações recebidas, entre atenderem ou não as suas necessidades. Nota-se que esses não estão satisfeitos com as informações recebidas.

As divulgações feitas nas páginas institucionais, tanto da Pró-Reitoria de Extensão e Cultura na Reitoria, quanto a página institucional do campus pesquisado, mostraram nas perguntas 18 está como "raramente" quanto ao acesso da Proext e "frequentemente" na pergunta 19 sobre o acesso à página do campus. Tal dado mostra que o discente tem mais percepção de acesso/participação com as informações divulgadas na página institucional do próprio campus.

No que se refere à ação de extensão mais conhecida, ficou evidente que os projetos estão em primeiro lugar dentre as atividades de extensão, seguido pelos programas. Com a possibilidade de ofertar bolsas, isso se torna um atrativo maior entre eles. Destarte, identifica-se que, na extensão, existem outras formas de atuação, entre essas, está a de prestação de serviços, com o menor nível de conhecimento. Os eventos e os cursos estão com bom nível de conhecimento, seguidos de visitas técnicas e estágio. De acordo com as diretrizes de extensão publicadas pela Resolução MEC/CNE/CES ํo 7, de 18 de dezembro de 2018, os estágios e as visitas técnicas não estão entre as diretrizes da extensão. Na sequência, apresentam-se os dados na figura 3 , que mostra a percepção dos discentes quanto às ações de extensão conhecidas pelos mesmos: 


\section{N

ISSN: 1984-6444 | http://dx.doi.org/10.5902/1984644463197

Figura 3 - Ações de extensão conhecidas

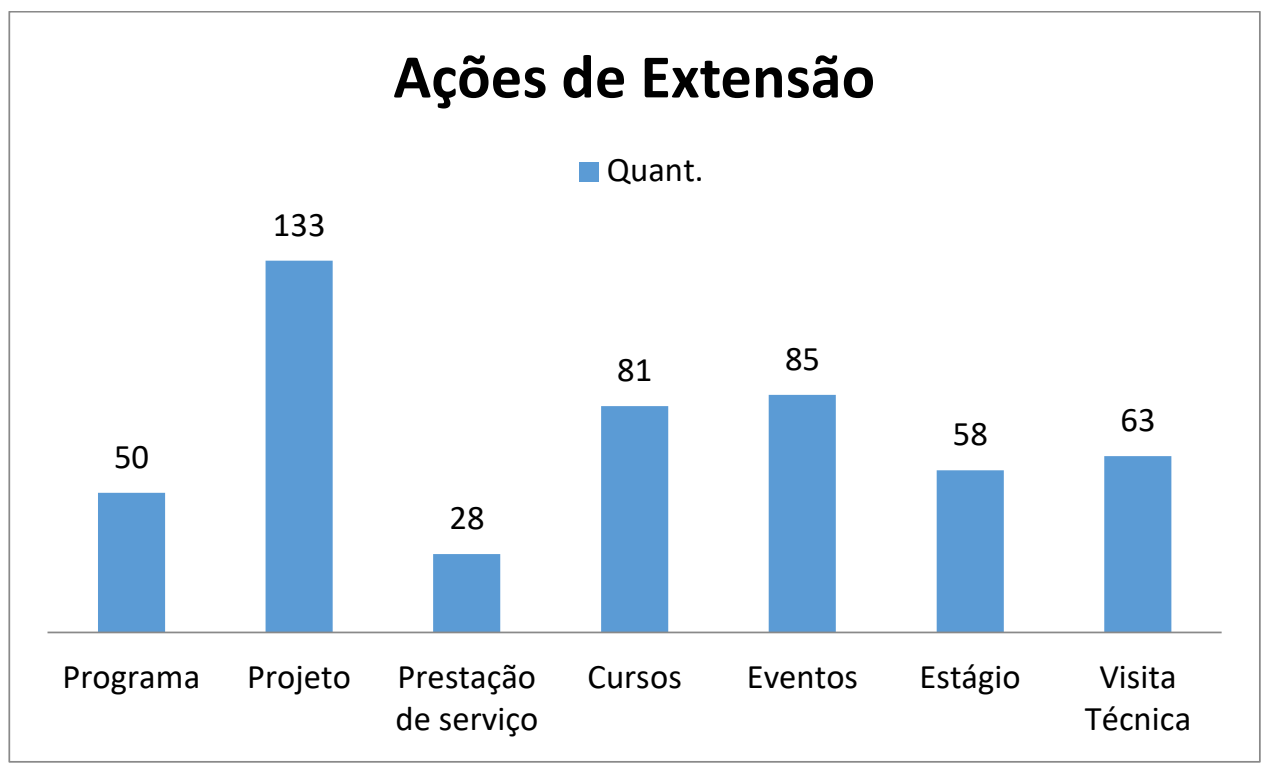

Fonte: Elaborado a partir do questionário aplicado durante a pesquisa de novembro 2019 a abril 2020.

Dentre as atividades de extensão proporcionadas pelo campus, destacam-se os projetos de extensão em nível de conhecimento e de divulgação entre os discentes. Observa-se que são divulgadas, na página institucional, as ações de prestação de serviços, mesmo sendo a de menor conhecimento entre os discentes, como ação de extensão.

\section{Percepção das Diretrizes da Extensão pelos Discentes}

$\mathrm{Na}$ segunda parte do questionário, direcionada aos 148 discentes que praticaram a extensão no campus, buscou-se analisar a percepção com relação às diretrizes da extensão, por meio das questões de 21 a 31. Apresenta-se, na figura 4, a percepção dos discentes pesquisados com relação às diretrizes da extensão. 


\section{$\sim$ usm 2

ISSN: 1984-6444 | http://dx.doi.org/10.5902/1984644463197

Figura 4 - Diretrizes Discentes

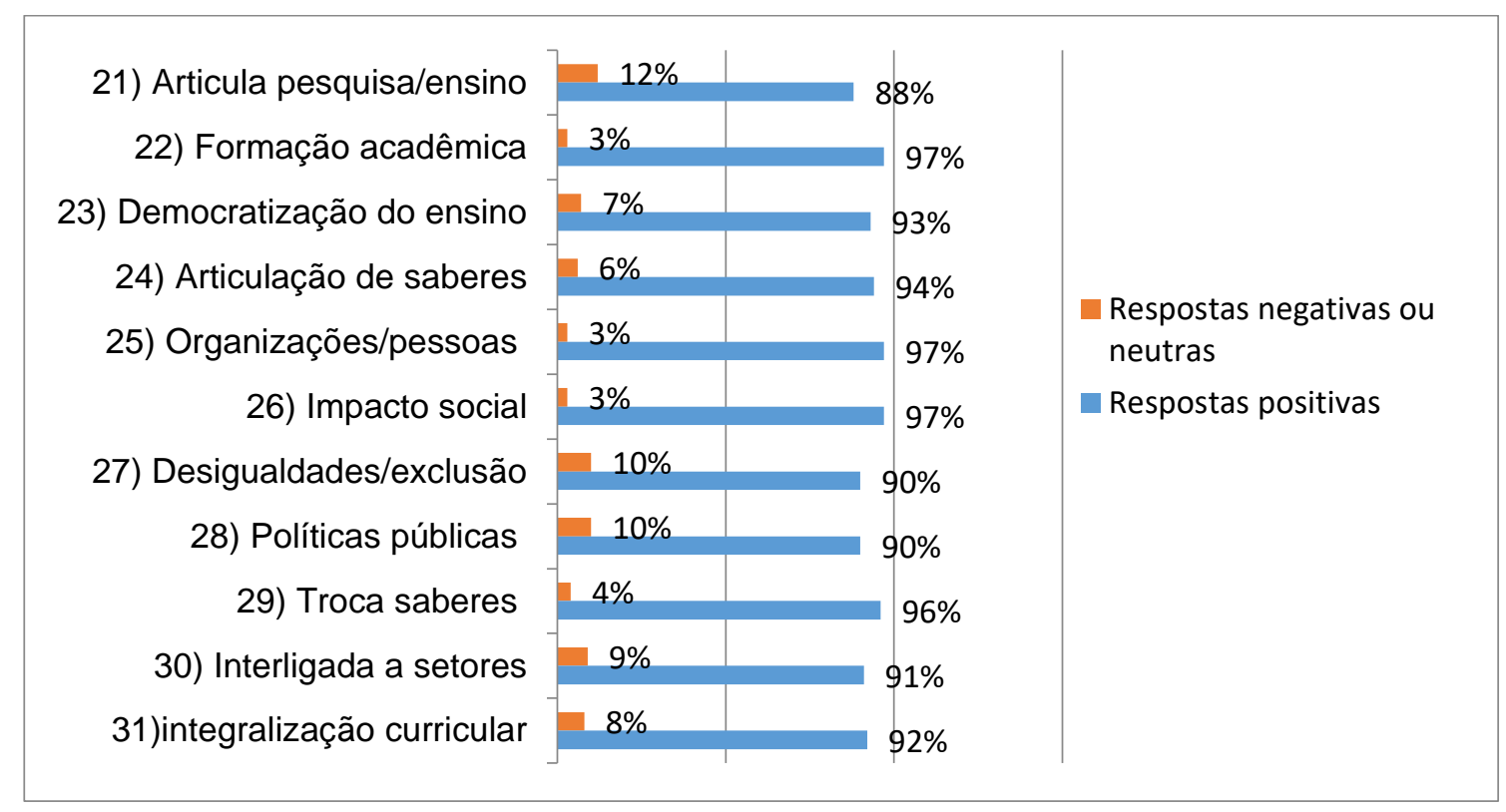

Fonte: Elaborado a partir do questionário aplicado durante a pesquisa de novembro 2019 a abril 2020

Nessa parte da pesquisa, as notas likert estão de 8,96 a 9,62; nota-se que os discentes que conhecem a extensão, identificaram como "sempre" quanto à percepção das diretrizes da extensão.

Quanto à percepção, relativa à indissociabilidade entre o ensino, a pesquisa $\mathrm{e}$ a extensão, nas perguntas de 21, 22, 23, 24 e 26, constatou-se que os discentes percebem essa diretriz, mas referendando as perguntas 21,27 e 28, percebeu-se a interação maior com o ensino do que com a pesquisa, sendo constatado por um maior número de respostas neutras ou negativas nessas perguntas. Notou-se uma redução na percepção com relação às transformações e impactos que as ações de extensão promovem, entretanto, tais dados só podem ser comprovados quando realizarem pesquisas nas comunidades, após estas ações.

Esta pesquisa apresenta as percepções dos discentes com relação às diretrizes da extensão, quanto à sua formação acadêmica, em que a interdisciplinaridade, a troca de saberes e a interação dialógica, estão sendo bem identificadas, com médias de respostas no nível de "sempre". Isso pode evidenciar que as práticas extensionistas estão somando positivamente. 


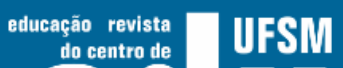

ISSN: 1984-6444 | http://dx.doi.org/10.5902/1984644463197

\section{Percepção do Impacto das ações de extensão na formação discente}

Tomando por base que dentre os cursos pesquisados, quatro são de licenciaturas, Azevedo et al. (2018) inferem que é na extensão universitária que o professor em formação conhece os desafios docentes e busca se construir no seu exercício profissional, levando, à comunidade, os conhecimentos teóricos absorvidos durante sua formação. A partir daí, surge a compreensão de que maneira estes conhecimentos podem colaborar na prática, por desenvolver o entendimento crítico sobre o contexto atual.

Analisando o cenário do impacto para os docentes, na terceira parte do questionário, na figura 5, 148 discentes se identificaram como praticantes da extensão. Assim, buscou-se analisar a percepção dos discentes com referência ao impacto que as atividades de extensão proporcionam aos mesmos.

Figura 5 - Impactos Discentes

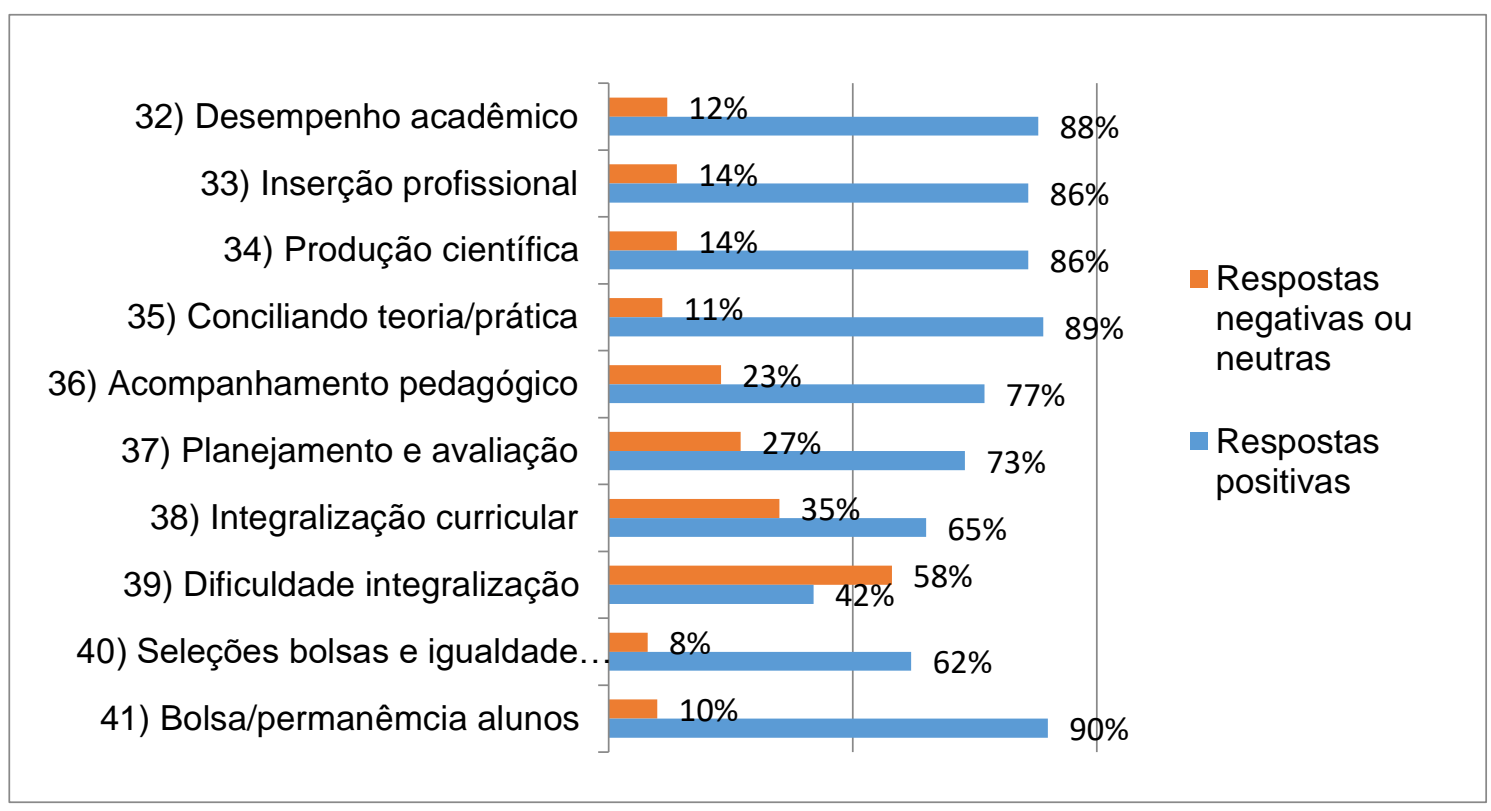

Fonte: Elaborado a partir do questionário aplicado durante a pesquisa de novembro 2019 a abril 2020

Para tais análises, a média Likert ficou entre 5,02 a 9,13, estando no nível de "não sabe", "raramente" e "sempre", encontrando-se menor percepção quando 


\section{Uism

ISSN: 1984-6444 | http://dx.doi.org/10.5902/1984644463197

Na Figura 6, com os resultados da pergunta de número 42, aplicada para ser analisada individualmente, buscou-se identificar o principal motivo que dificulta a participação dos 218 discentes em praticarem a extensão:

Figura 6 - Motivos que dificultam a participação na extensão

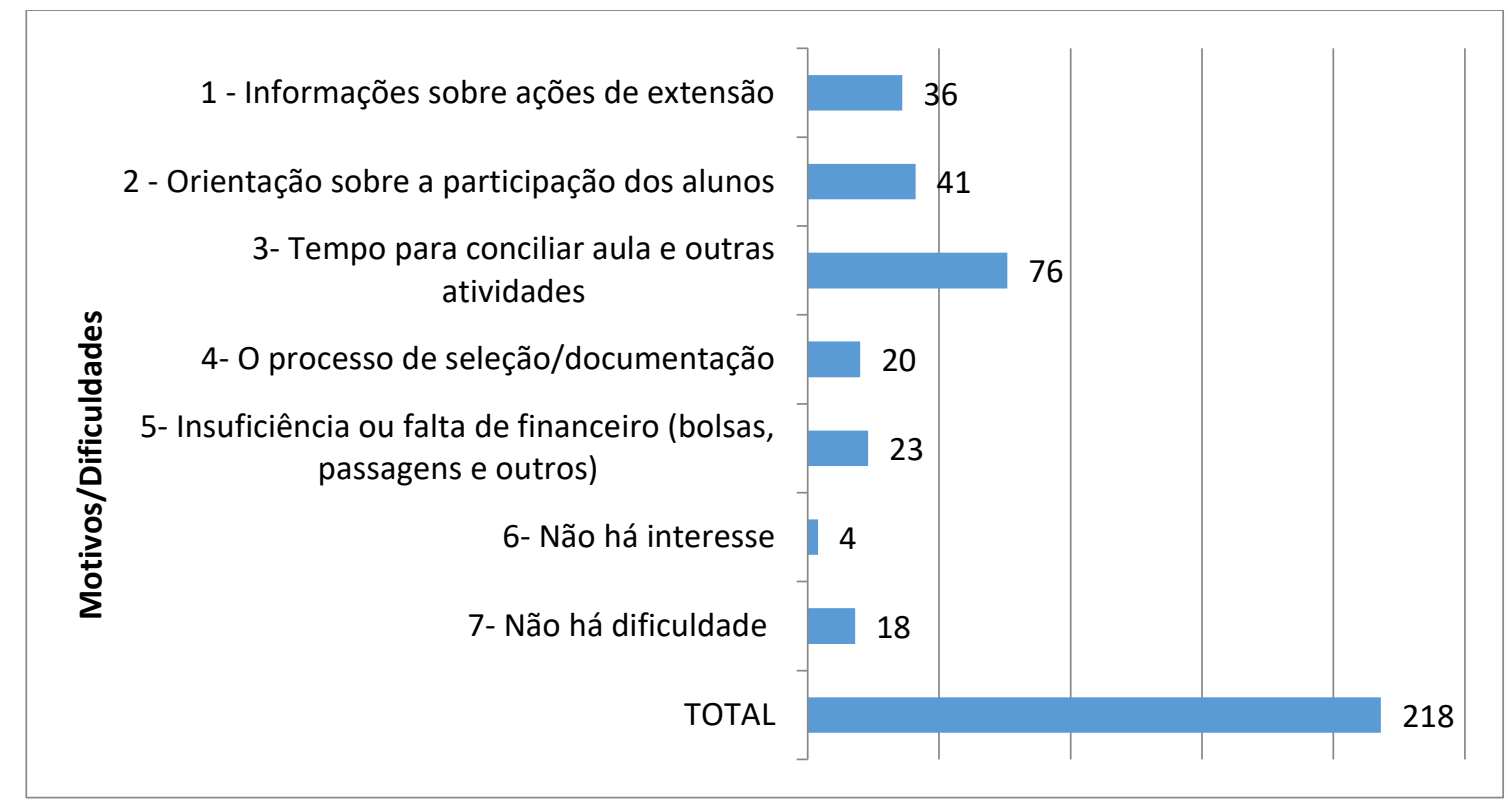

Fonte: Elaborado a partir do questionário aplicado durante a pesquisa de novembro 2019 a abril 2020

Em se tratando do motivo que dificultou a participação dos discentes nas práticas extensionistas, ficou evidente que o tempo disponível para conciliar as atividades curriculares com as ações de extensão é o fator mais impactante.

Como segundo motivo, apareceram as orientações e informações de como participar de tais ações, aspecto que merece atenção, pois sem o conhecimento do conceito de extensão e das normas institucionais, os discentes não encontram estímulos para praticá-las. Nota-se também que os discentes mostraram dificuldades em identificar as atividades que podem enquadrar-se como extensão. Nesse ponto, a comunicação é fundamental e merece ser mais bem trabalhada, buscando alternativas para disseminar o conceito, as diretrizes e as possibilidades, ampliando o entendimento das políticas institucionais e de extensão perante os discentes. 


\section{OF LFH ollubará}

ISSN: 1984-6444 | http://dx.doi.org/10.5902/1984644463197

Quanto à falta de apoio financeiro e a seleção para participar das ações de extensão, entende-se que, dentre as atividades mais conhecidas, estão os projetos, que podem ser desenvolvidos mediante bolsas de extensão. Para esse tipo de seleção, existem normas próprias para discentes e docentes; a seleção pode ser uma dificuldade para aqueles que não se enquadram nas regras, ficando outra opção, os projetos com estudantes voluntários, que são executados sem a viabilização de bolsas. Existem outras possibilidades para serem trabalhadas como ações de extensão, resta saber o porquê de serem atrativas.

Dentro das IES, existe a Assistência Estudantil que segue as regulamentações do governo para proporcionar políticas assistidas, visando à permanência e ao êxito para discentes que se enquadram nas regras. Nota-se que os discentes participantes da pesquisa demonstraram desconhecimento das oportunidades disponibilizadas, para que consigam participar das atividades de extensão de forma mais integralizada (IF SERTÃO-PE, 2020).

Com estas dificuldades apresentadas, chega-se a compreensão que o entendimento e conhecimento aprofundado da extensão acadêmica estão merecendo mais atenção. A comunicação para com os discentes necessita ser mais bem trabalhada, para que tanto os discentes que já estão na instituição quanto os ingressantes, percebam as possibilidades de se atuar na extensão e os benefícios que estarão proporcionando, tanto para si como para as comunidades, com as possibilidades de transformações que a vivência extensionista disponibiliza.

\section{Análises Docentes}

Seguem as análises dos resultados da percepção dos docentes com relação à extensão quanto a Acesso/Participação e Diretrizes, organizados em seções. Inicialmente, será apresentada a percepção dos docentes com relação à extensão, que é Acesso/Participação, localizado na primeira parte do questionário com as perguntas de 5 a 12; na segunda parte, estão os resultados da percepção quanto às Diretrizes da extensão, com as questões de 14 a 26. 


\section{N-Tis

ISSN: 1984-6444 | http://dx.doi.org/10.5902/1984644463197

Para a análise da qualidade dos cenários Acesso/Participação e Diretrizes no conjunto de perguntas, aplicou-se Alpha de Cronbach, seguindo orientações de Vieira (2018), obtendo-se para acesso/participação 0.78, e diretrizes 0,82, respectivamente, sendo os questionários bem avaliados e dimensionados. Quanto às análises, utilizouse a escala de atitude Likert. Ela indica o grau de opinião em relação à pergunta direcionada com nota ponderada de 0 a 10. As questões de 5 a 12, sobre percepção de acesso e participação nas ações de extensão, foram destinadas a todos os participantes da pesquisa; as perguntas de 14 a 26, quanto às diretrizes da extensão, foram direcionadas aos que praticam atividades de extensão no campus.

Procurou-se identificar qual a percepção dos docentes com relação às atividades de extensão mais conhecidas ou praticadas e a maior dificuldade em praticá-las. Para a pesquisa, foram enviados questionários aos 90 (noventa) docentes que estavam em atividades nos cursos superiores do campus Petrolina, no segundo semestre do ano de 2019.

\section{Percepção Acesso/Participação dos Docentes}

Nas análises quanto ao acesso/participação, ficou evidenciado que dos 36 docentes que responderam a pesquisa, dois não conheciam a extensão praticada pelo campus. Apresenta-se, na figura 7, a percepção dos docentes que participaram da pesquisa, correspondendo a $94 \%$ de forma positiva, como conheciam ou praticavam atividades de extensão: 


\section{DIsw

ISSN: 1984-6444 | http://dx.doi.org/10.5902/1984644463197

Figura 7 - Conhecimento em relação à extensão

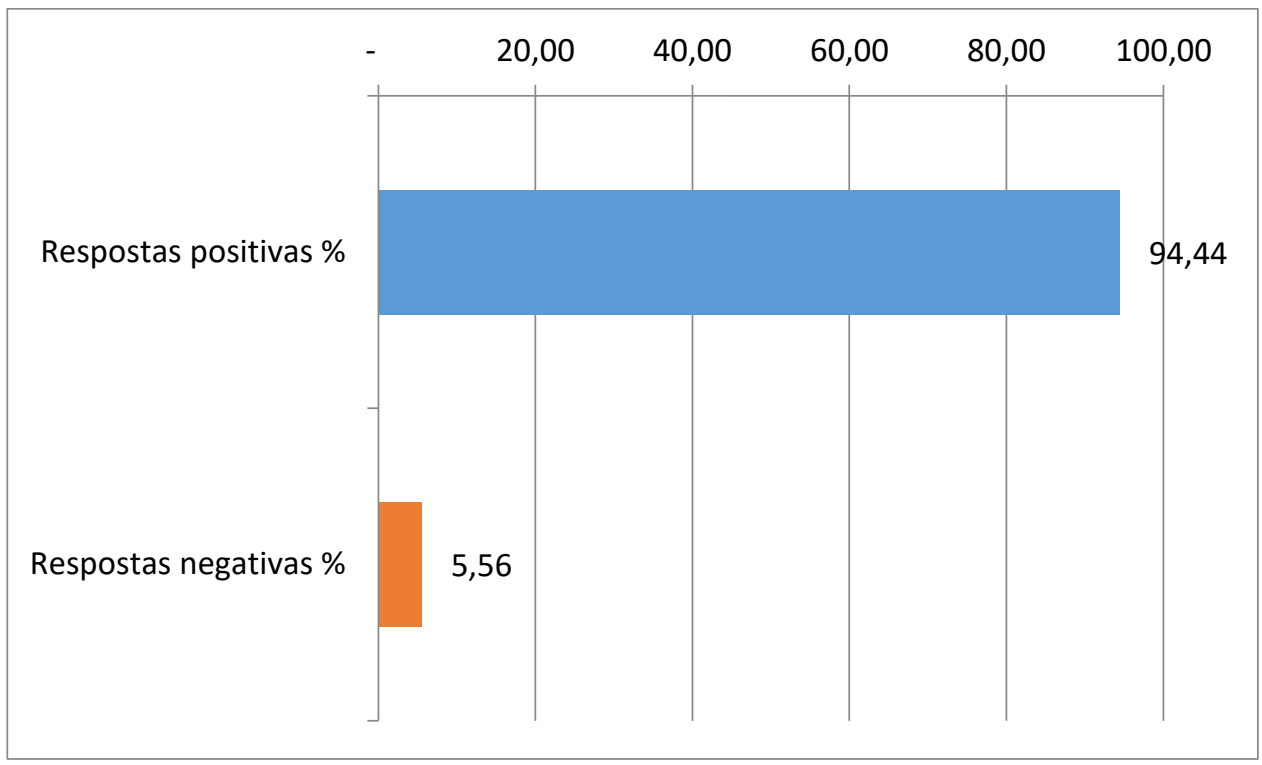

Fonte: Elaborado a partir do questionário aplicado durante a pesquisa de novembro 2019 a abril 2020

A pesquisa buscou identificar a percepção desses docentes quanto às informações e condições disponibilizadas para as práticas extensionistas no campus Petrolina, sendo explanada na Figura 8:

Figura 8 - Condições de atuação e informações recebidas

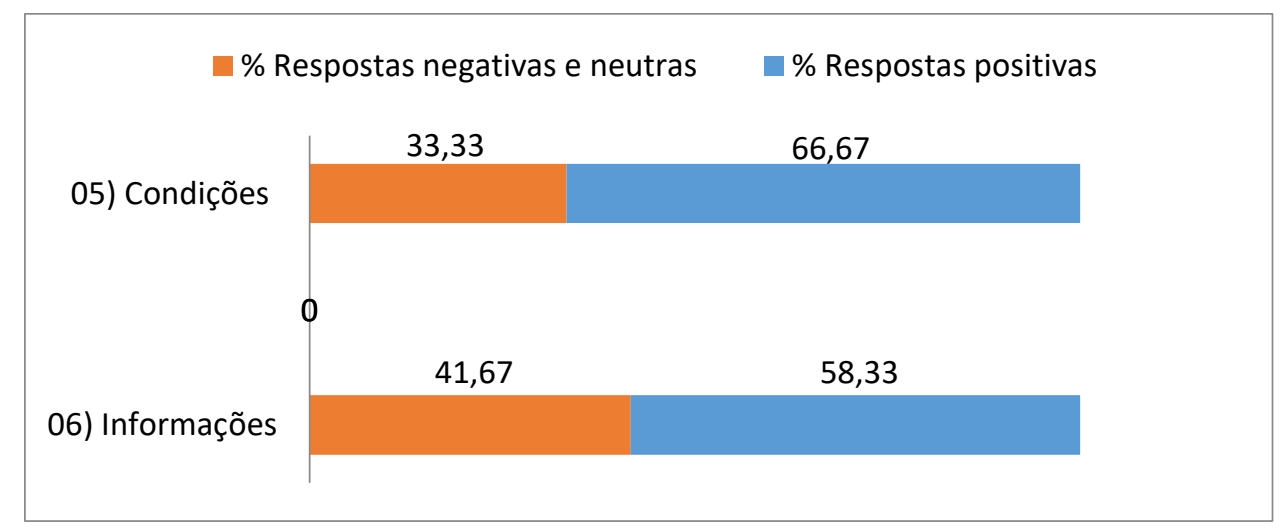

Fonte: Elaborado a partir do questionário aplicado durante a pesquisa de novembro 2019 a abril 2020 


\section{OF HEM

ISSN: 1984-6444 | http://dx.doi.org/10.5902/1984644463197

Sobre as condições para se executar a extensão proporcionada pelo campus com a pergunta número 5 , os docentes apontaram como positivamente, mas quando perguntado sobre as informações recebidas por meio da questão 06, as análises mostram os docentes mais insatisfeitos. Na questão seis, os docentes revelaram que as informações recebidas não atenderam às necessidades deles. Mais uma vez, a comunicação foi apontada com falha nesse processo, algo que foi identificado também nas análises discentes. As informações podem ter sido repassadas aos docentes, mas esses não compreenderam ou não estão satisfeitos com a forma dessa comunicação.

A Figura 9, com as 7 a 12 que foram direcionadas aos docentes participantes da pesquisa, objetivou identificar a percepção destes com relação ao acesso/participação nas atividades extensionistas:

Figura 9 - Acesso/Participação Docente

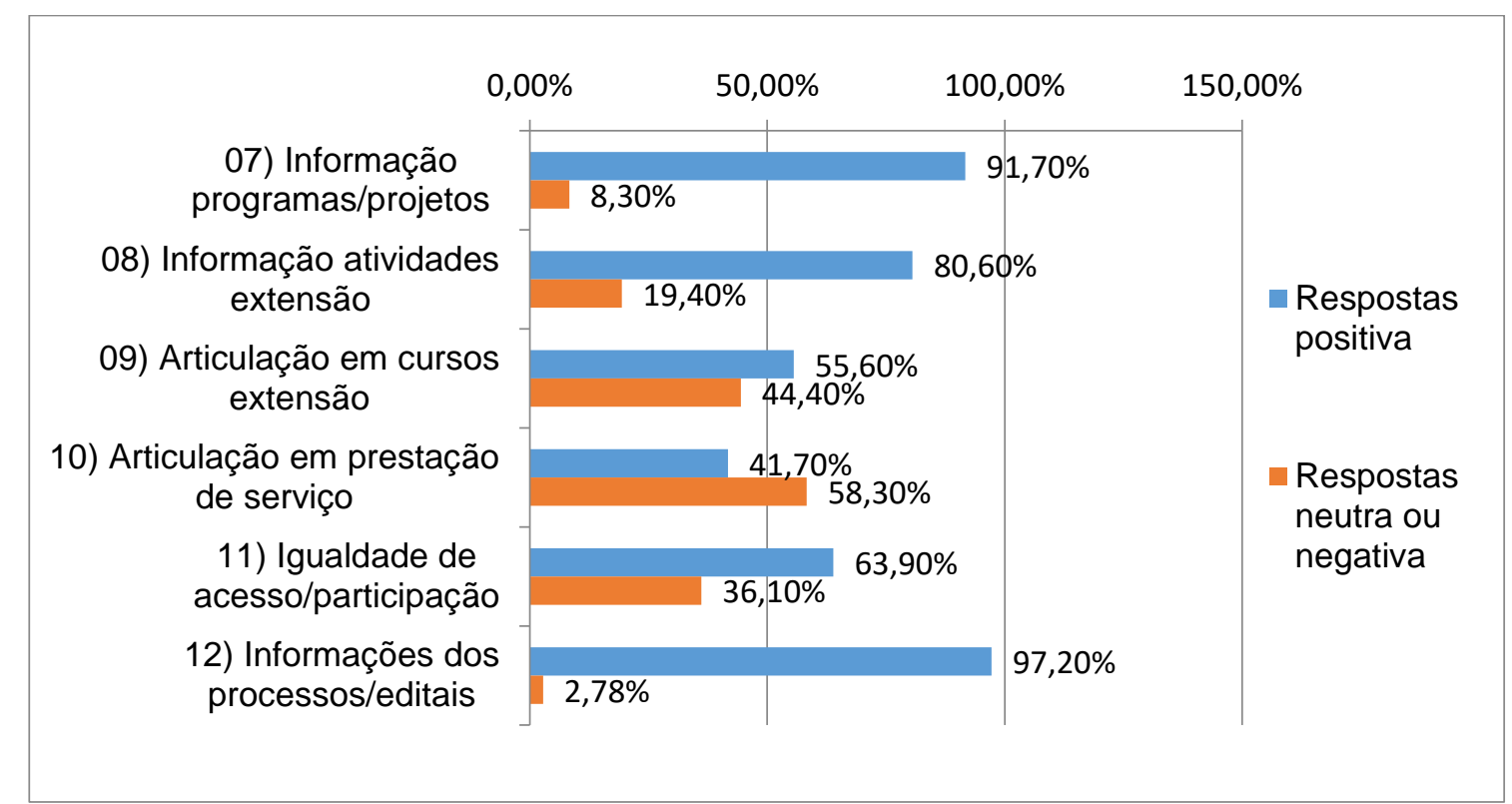

Fonte: Elaborado a partir do questionário aplicado durante a pesquisa de novembro 2019 a abril 2020

Comparando as respostas 7 com Likert 8,33 e 8 com Likert 7,29, quanto ao Acesso/Participação nas atividades de extensão desenvolvidas pelo campus, apresentaram-se como "frequentemente" quanto ao recebimento de informações sobre as possibilidades de atuação com programas ou projetos de extensão, na resposta da pergunta 6 , quanto a ficar sabendo sobre as atividades de extensão que 


\section{N-T

ISSN: 1984-6444 | http://dx.doi.org/10.5902/1984644463197

são realizadas no campus, $58,33 \%$ estão respondendo mais positivamente, ou seja, estão satisfeitos com as informações recebidas.

As questões 9 e 10 encontram-se com as médias Likert 5, 28 e 4,17, no nível de "não sabe"; quando perguntados sobre a participação como principal articulador em cursos de extensão e prestação de serviços, apresentou as menores médias. Nas práticas extensionistas, o discente é o protagonista da ação, tendo um docente como orientador. Essa ação necessita de planejamento e o orientador é quem traça este caminho em conjunto com o orientando nas ações de execução, acompanhamento e conclusão.

$\mathrm{Na}$ figura 10, a questão direcionada aos docentes para identificar qual ação de extensão conhece, a prestação de serviços apresentou-se com menor nível de conhecimento em relação a programas, projetos, cursos, eventos, estágios e visitas técnicas. Observou-se que no item 11, na figura 9, quanto à igualdade de acesso, os docentes estão identificando como "frequentemente". Para tais atividades, as seleções seguem as normas estipuladas nos editais, com atendimento das exigências e elas podem oferecer dificuldade aos interessados. Seria necessário um estudo aprofundado quanto às exigências, se estão ajudando ou dificultando tais participações, deixando sugestões de aprofundamento para pesquisas futuras. A Figura 10 mostrou as ações de extensão mais conhecidas perante os docentes da pesquisa. 


\section{usm

ISSN: 1984-6444 | http://dx.doi.org/10.5902/1984644463197

Figura 10 - Ações de extensão conhecidas

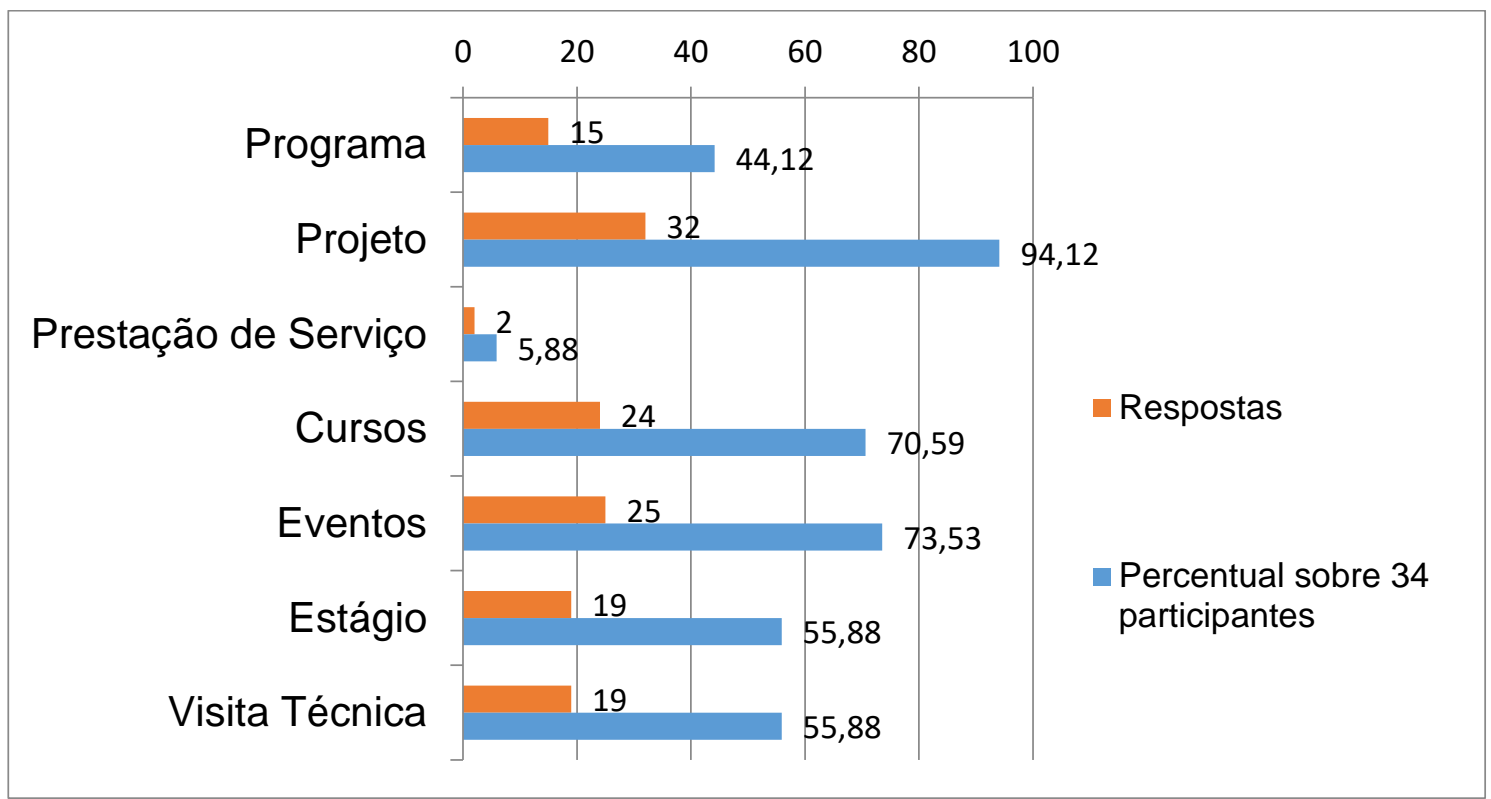

Fonte: Elaborado a partir do questionário aplicado durante a pesquisa de novembro 2019 a abril 2020

Em sua pesquisa, Oliveira (2016) identificou os saberes didático-pedagógicos para o exercício da docência, voltados para o desenvolvimento de projetos de extensão pelos não licenciados. Constatou, nas falas dos pesquisados, que nem sempre a docência foi o primeiro caminho escolhido por esses profissionais que ingressaram na educação profissional e tecnológica. Esse caminho Ihes proporciona uma trajetória de descobertas permeadas por experiências vividas com a prática da docência, desafiando-os a reinventar-se, mas identificou, também, a necessidade de a instituição oferecer condições possíveis para o desenvolvimento dessas atividades.

Dentre as atividades de extensão, as mais conhecidas pelos docentes foram os projetos, cursos e eventos. Os docentes podem completar sua carga horária com cursos livre de extensão ou de formação inicial e continuada, com eventos envolvendo os discentes e a comunidade, entretanto, o mais conhecido por esses docentes, está o projeto de extensão. 


\section{Lusm

ISSN: 1984-6444 | http://dx.doi.org/10.5902/1984644463197

\section{Percepção Diretrizes da extensão pelos docentes}

Quanto à percepção dos docentes em relação às diretrizes da extensão, dos 36 participantes, dois responderam que não conheciam as ações de extensão no campus Petrolina. Dentre esses docentes, 75\% deram nota likert de 5,96 a 8,08, ficando com percepção de "não sabe" a "raramente" e 25\% deram nota entre 8,97 a 9,56, ficando com percepção de "sempre". Sobre isso, veja a figura 11 :

Figura 11 - Diretrizes Docentes

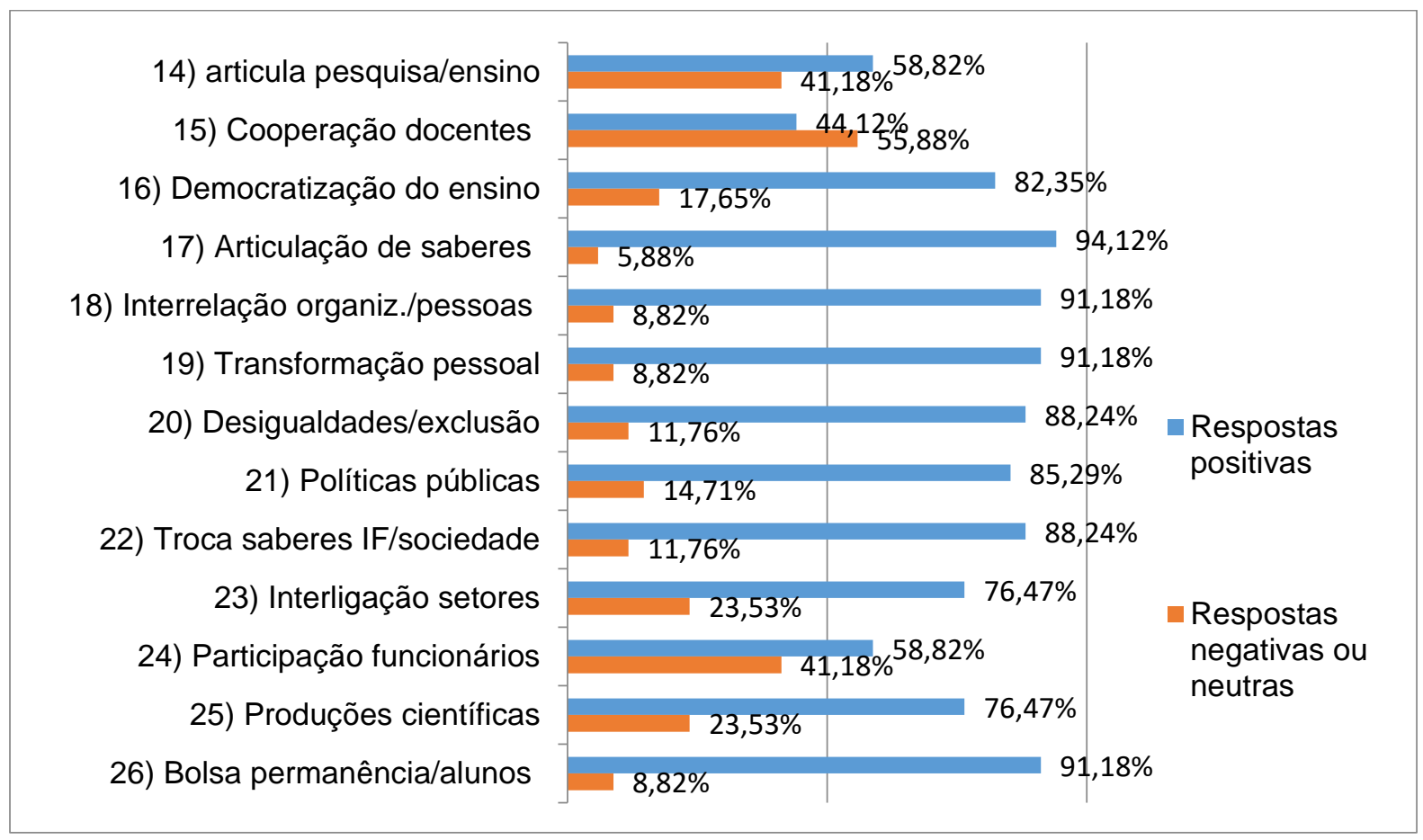

Fonte: Elaborado a partir do questionário aplicado durante a pesquisa de novembro 2019 a abril 2020

Nas perguntas 14, 15 e 24, o nível de percepção está em "não sabe" a "raramente". Elas remetem à interdisciplinaridade, ou seja, os docentes estão com dificuldades para articular as disciplinas, metodologias e a cooperação entre eles para executar as atividades extensionistas. Da forma como são apresentadas as ações de extensão, verifica-se que muitas têm somente um docente como orientador, situação justificada pelas porcentagens de respostas neutras e negativas nas perguntas 14, 15 e 24. 


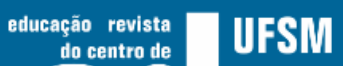

ISSN: 1984-6444 | http://dx.doi.org/10.5902/1984644463197

As análises apontaram que os docentes reconheceram as diretrizes da extensão e suas contribuições na formação e na vida do discente, e como essas práticas podem contribuir nas transformações perante as comunidades onde são executadas, identificados nas respostas 16 a 23.

As atividades extensionistas têm o discente como principal interlocutor, sempre sob a orientação do docente. O planejamento para essas ações é fundamental, muitas dessas requerem mais que tempo e dedicação, requerem também insumos e transporte. Quando se analisam as respostas na figura 12, com relação aos motivos que mais dificultam a participação dos docentes nas atividades extensionistas, verificou-se que o tempo para conciliar as atividades representou 44,4\% seguido de insuficiência ou a falta de apoio financeiro, indicando 13,9\%.

Figura 12 - Motivos que dificultam que os docentes participem da extensão

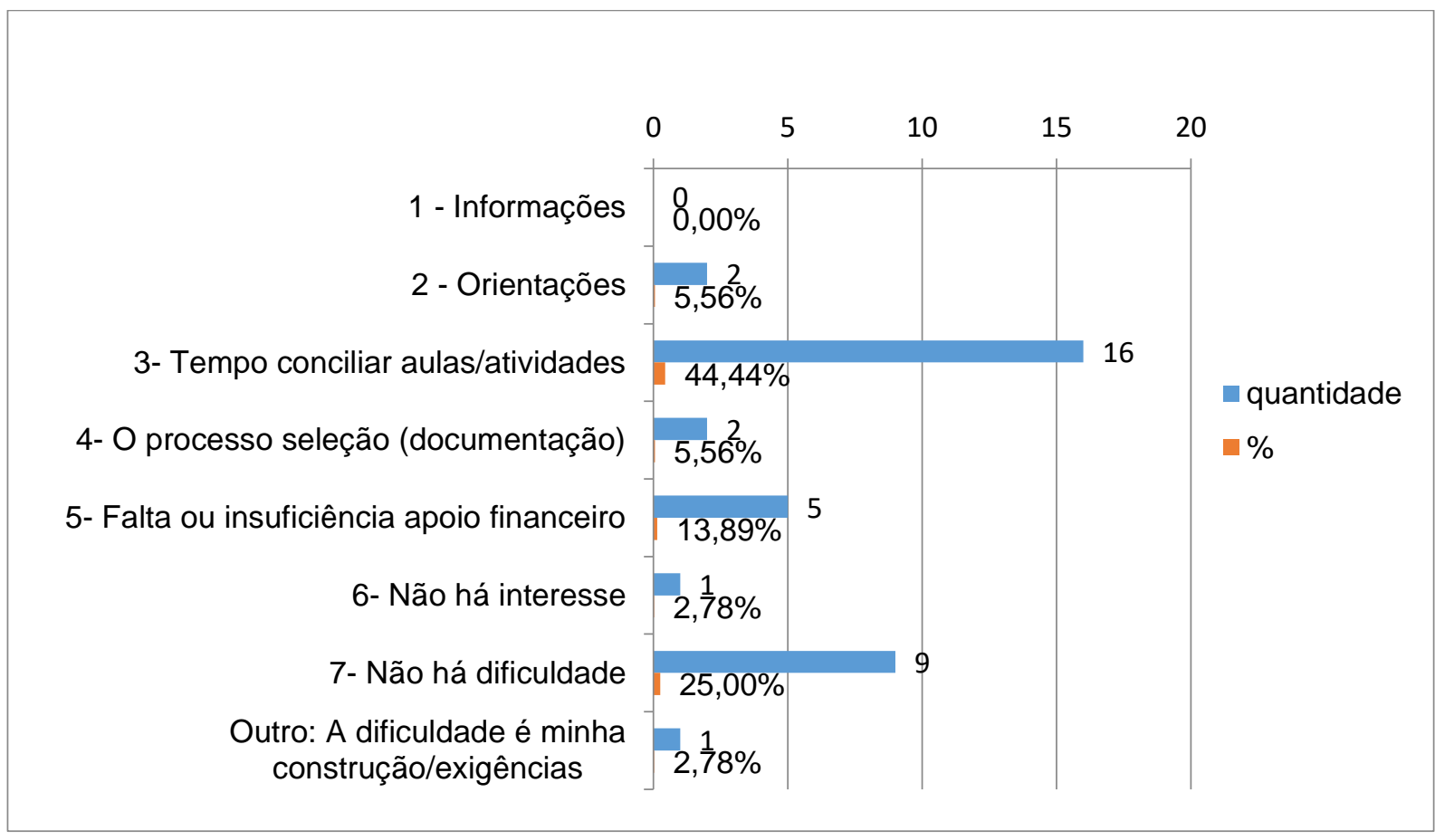

Fonte: Elaborado a partir do questionário aplicado durante a pesquisa de novembro 2019 a abril 2020 


\section{Aillbapẫ \\ 3}

ISSN: 1984-6444 | http://dx.doi.org/10.5902/1984644463197

\section{Considerações finais}

Esta pesquisa buscou trazer um recorte da percepção da extensão por parte dos discentes e docentes do IF Sertão-PE, campus Petrolina. Entende-se que os resultados obtidos nas análises, possam colaborar no aprimoramento e desempenho extensionista da instituição. Durante a pesquisa, foram identificados aspectos positivos e fragilidades. Por um lado, pôde-se identificar como a extensão, mesmo não estando ainda totalmente normatizada e institucionalizada, mostra-se politicamente ativa e engajada em desenvolver-se nas práticas com várias ações dentro e fora da instituição, cumprindo seu papel articulador, comprometida com as problemáticas sociais.

Por outro lado, lacunas foram identificadas e apontadas nos cenários analisados, mostrando que ainda existem discentes desconhecendo tanto a extensão, como as possibilidades de se atuar com atividades que se enquadram neste contexto. As médias menores, na escala likert, foram as relacionadas ao acesso/participação. Nesse aspecto, a comunicação merece mais atenção, nota-se que os discentes não estão totalmente satisfeitos com as informações recebidas, desconhecendo todas as possibilidades de práticas extensionistas, assim como aqueles que a praticam, estão com dificuldades na integralização curricular dessas atividades.

Para aqueles discentes que praticam a extensão, conseguem perceber as possibilidades transformadoras que a extensão traz, tanto para eles, como para as comunidades. No que se refere ao impacto, os discentes identificam o quanto a extensão pode agregar à sua formação, apesar de existirem dúvidas em relação à integralização de créditos dessas atividades, quanto ao acompanhamento e planejamento; mais uma vez, a comunicação é apontada com indícios de que não atingiu seu intuito.

Esse estudo também permitiu entender, que a falta de pesquisas, após as atividades extensionistas, se faz presente nestas percepções, gerando assim, uma lacuna de conhecimento quanto à diretriz da integração dialógica que precisa ser mais trabalhada perante os interlocutores da extensão. 


\section{Tism outibahá

ISSN: 1984-6444 | http://dx.doi.org/10.5902/1984644463197

Quanto às informações por parte das possibilidades de se praticar extensão, esse dado revela que merece mais atenção, a divulgação e o entendimento de como podem participar, evitando dúvidas ou impedindo tais participações, assim como a cooperação entre eles, na articulação entre a extensão, o ensino e a pesquisa.

Passando para os docentes, a pesquisa aponta que estes identificam as diretrizes da extensão e a importância destas ações, entretanto, a falta de tempo para conciliar as atividades está sendo o fator apontado como um bloqueio entre os pesquisados, seguido de apoio financeiro para essas práticas. Existem possibilidades de apoio financeiro que são ofertadas pela instituição e podem estar passando despercebidas ou desconhecidas pelos docentes, ou até mesmo com dificuldades de acesso.

Para Chesani et al. (2017), a indissociabilidade entre a extensão, a pesquisa e o ensino provocam, nos docentes e discentes, o despertar no envolvimento entre o saber da experiência, o saber do conhecimento e o saber pedagógico, beneficiando os interlocutores e a comunidade no processo de educação continuada. Para eles, não se pode considerar que a extensão, o ensino e a pesquisa sejam acessórios uma da outra, elas se complementam, levando e trazendo o conhecimento articulado com a interação dialógica entre a universidade e a sociedade.

\section{Referências}

AGGIO. Juliana Ortega, Conhecimento Perceptivo segundo Aristóteles, 2006. 118 f. Dissertação (Mestrado em Filosofia) - Universidade de São Paulo. Disponível em: https://teses.usp.br/teses/disponiveis/8/8133/tde-10012008-114644/pt-br.php. Acesso em: 20 jun 2020.

AZEVEDO, Bárbara Delgado. et al. Extensão Universitária e formação de professores: um intercâmbio enriquecedor de conhecimento entre escola e universidade - RÓNAl: Revista de Estudos Clássicos e Tradutórios, 2019 V.7 N.1 - pp. 51 -60 - UFJF JUIZ DE $\quad$ FORA. Disponível em: https://periodicos.ufjf.br/index.php/ronai/article/view/23292. Acesso em: 1ํ maio 2020. 


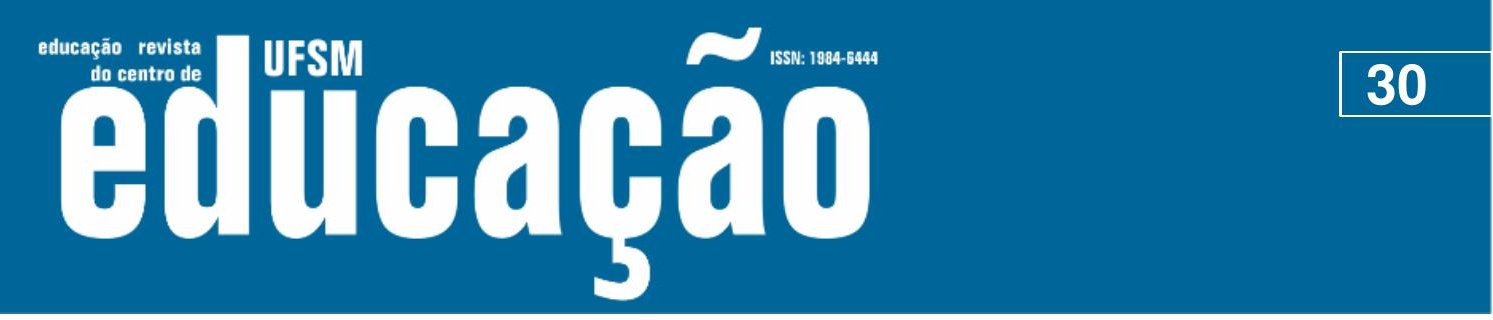

ISSN: 1984-6444 | http://dx.doi.org/10.5902/1984644463197

BARBOSA, Valeska Cristina. Extensão Universitária: proposição e validação de um instrumento de avaliação da percepção dos discentes. 2012. 131f. Dissertação (Mestrado em Administração) Universidade FUMEC. Faculdade de Ciências Empresariais, Belo Horizonte, 2012. Disponível em: http://www.fumec.br/revistas/pdma/article/viewFile/4466/2279. Acesso em: 6 set. 2018.

BRASIL. [Constituição (1988)]. Constituição da República Federativa do Brasil. Brasília, DF; Disponível em: http://www.planalto.gov.br/ccivil_03/constituicao/constituicaocompilado.htm. Acesso em: 6 maio 2020.

BRASIL. MEC Ministério da Educação. SETEC Secretaria de Educação Profissional e Tecnológica, 2018. Disponível em: http://portal.mec.gov.br/setec-secretaria-deeducacao-profissional-e-tecnologica. Acesso em: 10 set. 2018.

BRASIL. MEC Ministério da Educação. CNE/CES. Resolução nº 7, de 18 dezembro de 2018.2 Disponível em:http://portal.mec.gov.br/index.php?option=com_docman\&view=download\&alias=1 04251-rces007-18\&category_slug=dezembro-2018-pdf\&Itemid=30192. Acesso em: 1ำ maio 2020.

BRASIL. Lei de criação da Rede Federal de Educação Profissional, Cientifica e Tecnologica. Lei 11.982 de 29 de dezembro de 2008. Disponível em: http://www.planalto.gov.br/ccivil_03/_Ato2007-2010/2008/Lei/L11892.htm. Acesso em: 8 maio 2020.

BRASIL. Lei de Diretrizes e Bases da Educação Nacional, Lei 4024 de 20 de dezembro de 1961. Disponível em: https://www2.camara.leg.br/legin/fed/lei/19601969/lei-4024-20-dezembro-1961-353722-publicacaooriginal-1-pl.html

BRASIL. Lei de Diretrizes e Bases da Educação Nacional, Lei 9394 de 20 de dezembro de 1996. 1 Disponível em: http://www.planalto.gov.br/ccivil_03/leis/l9394.htm. Acesso em: 10 maio 2020.

CHESANI, F. H. et al., A indissociabilidade entre a extensão, o ensino e a pesquisa: o tripé da universidade, Revista Conexão UEPG, Ponta Grossa, v. 13 n.3 - set./dez. 2017. Disponível em: http://www.revistas2.uepg.br/index.php/conexão, Acesso em: 8 maio 2020.

FREIRE, Paulo. Extensão ou comunicação? 1968, tradução Rosiska Darcy de Oliveira. Rio de Janeiro. ed. Paz e Terra, 2013. 89 p. Título Original: Extención o comunicación? ISNB 979-85-7753-222-3 (recurso eletrônico). Disponível em: https://www.academia.edu/38319324/Paulo_Freire_-

_Extens\%C3\%A3o_ou_comunica\%C3\%A7\% \%C3\%Ā3o_.pdf. Acesso em: 1ํago. 2018 


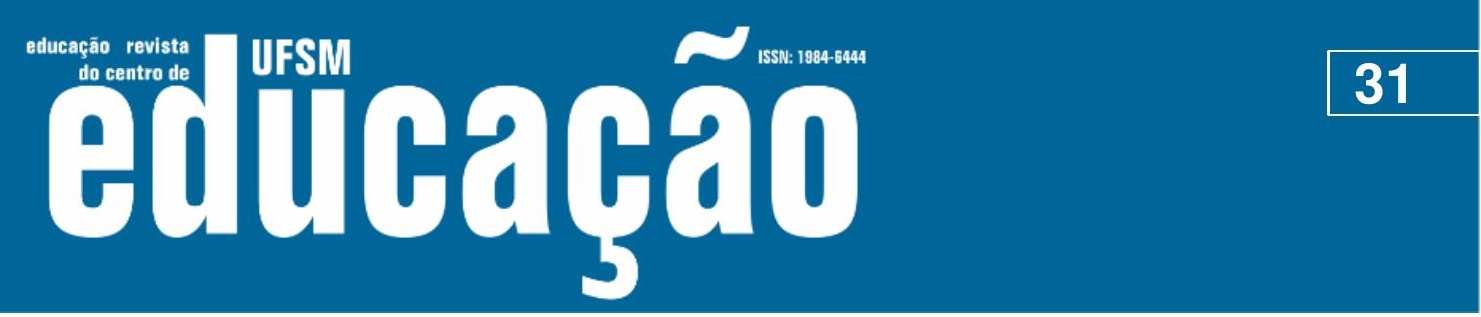

ISSN: 1984-6444 | http://dx.doi.org/10.5902/1984644463197

INSTITUTO FEDERAL DO SERTÃO PERNAMBUCANO-IFSERTÃO-PE. Estatuto. Diário Oficial da União, Publicado em: 21/03/2019, Edição: 55, Seção: 1, p. 26. Disponível em: https://www.ifsertao-pe.edu.br/images/ProReitorias/Prodi/ESTATUTO\%20DO\%20IF\%20SERTO-PE\%20-

\%20Dirio\%200ficial\%20da\%20Unio.pdf. Acesso em: 10 maio 2020.

INSTITUTO FEDERAL DO SERTÃO PERNAMBUCANO-IFSERTÃO-PE. Campus Petrolina. Disponível em: https://www.ifsertao-pe.edu.br/index.php/extensao-pet. Acesso em: 25 maio 2020.

INSTITUTO FEDERAL DO SERTÃO PERNAMBUCANO-IFSERTÃO-PE. PROEXT Pró-Reitoria de Extensão e Cultura. Disponível em: https://www.ifsertaope.edu.br/novosite/index.php/a-instituicao/noticias-em-destaque/9804-abertura-jincejid-2019. Acesso em: 10 out. 2019.

INSTITUTO FEDERAL DO SERTÃO PERNAMBUCANO-IFSERTÃO-PE. IF SertãoPE. Página Institucional, A Instituição, Conselho Superior, Resoluções. Disponível em: https://www.ifsertao-pe.edu.br/index.php/cs-resolucoes. Acesso em 10 out. 2019.

OLIVEIRA, Rosilene Souza de., Ser professor na educação profissional e tecnologia: fazeres e saberes docentes do IF SERTÃO - PE, 2016, 183 f. UNEB. Dissertação (Mestrado em Educação e Diversidade), Disponível em: http://www.saberaberto.uneb.br/handle/20.500.11896/358 Acesso em 20 jun. 2020.

PRODANOV, Cleber Cristiano. FREITAS, Ernani Cesar. Metodologia do Trabalho Científico. Métodos e Técnicas da Pesquisa e do Trabalho Acadêmico, 2 ed. Novo Hamburgo: $\quad$ Feevale, 2013. Disponível em: http://www.feevale.br/Comum/midias/8807f05a-14d0-4d5b-b1ad-1538f3aef538/Ebook\%20Metodologia\%20do\%20Trabalho\%20Cientifico.pdf. Acesso em: 10 maio 2019.

SANTOS, Henrique de Souza; ROCHA, Bianca Ferreira; PASSAGLIO, Kátia Tomagnini, Extensão Universitária e Formação no Ensino Superior. Revista brasileira de Extensão universitária, v. 7, n 1, p. 23-28, jun. 2016. Disponível em: https://periodicos.uffs.edu.br/index.php/RBEU/article/view/3087. Acesso em: 10 ago. 2019.

VIEIRA, Sonia. Alpha de Cronbach. Blog Sonia Vieira, 2015. In: LNADIS, JR., KOCH, G. G. (1977). The measurement of observer agreement for categorical data. Biometrics. 33:150. Disponível em: http://soniavieira.blogspot.com/2015/10/alfa-decronbach.html. Acesso em: 10 maio 2020.

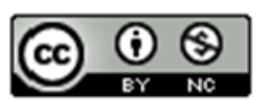

This work is licensed under a Creative Commons Attribution-NonCommercial 4.0 International (CC BY-NC 4.0) 